\title{
Inter-comparison of integrated water vapor from satellite instruments using reference GPS data at the Iberian Peninsula
}

\author{
Javier Vaquero-Martínez ${ }^{\mathrm{a}, \mathrm{b}, *}$, Manuel Antón ${ }^{\mathrm{a}, \mathrm{b}}$, José Pablo Ortiz de Galisteo ${ }^{\mathrm{c}, \mathrm{d}}$, \\ Victoria E. Cachorro ${ }^{\mathrm{d}}$, Pablo Álvarez-Zapatero ${ }^{\mathrm{d}}$, Roberto Román ${ }^{\mathrm{e}, \mathrm{f}}$, Diego Loyola ${ }^{g}$, \\ Maria João Costa ${ }^{h}$, Huiquin Wang ${ }^{i}$, Gonzalo González Abad ${ }^{i}$, Stefan Noël ${ }^{j}$ \\ a Departamento de Física, Universidad de Extremadura, Badajoz, Spain \\ b Instituto Universitario de Investigación del Agua, Cambio Climático y Sostenibilidad (IACYS), Universidad de Extremadura, Badajoz, Spain \\ c Agencia Estatal de Meteorologia (AEMET), Valladolid, Spain \\ d Grupo de Óptica Atmosférica, Universidad de Valladolid, Valladolid, Spain \\ e Department of Applied Physics, University of Granada, Granada, Spain \\ f Andalusian Institute for Earth System Research (IISTA-CEAMA), Granada, Spain \\ g German Aerospace Center (DLR), Oberpfaffenhofen, Germany \\ h Departamento de Física, Instituto de Ciências da Terra, Escola de Ciências e Tecnología, Universidade de Évora, Évora, Portugal \\ i Smithsonian Astrophysical Observatory, Cambridge, Massachusetts, United States \\ j Institute of Environmental Physics, University of Bremen, Bremen, Germany
}

\section{A R T I C L E I N F O}

\section{Keywords:}

Water vapor

Inter-comparison

IWV

GPS

Satellite

MODIS

OMI

GOME-2

SEVIRI

SCIAMACHY

AIRS

\begin{abstract}
A B S T R A C T
This paper focuses on the inter-comparison of integrated water vapor (IWV) products derived from the following satellite instruments: Global Ozone Monitoring Instrument (GOME-2), Moderate-Resolution Imaging Spectroradiometer (MODIS) on the Terra and Aqua satellites, Ozone Monitoring Instrument (OMI), Spining Enhanced Visible and InfraRed Imager (SEVIRI), Atmospheric Infrared Sounder (AIRS), and Scanning Imaging Absorption Spectrometer for Atmospheric Chartography (SCIAMACHY). IWV data from GPS in nine groundbased stations located in the Iberian Peninsula are used as reference. The study period extends from 2007 to 2012. The results show that, in general, OMI has good accuracy (pseudomedian of the relative differences between OMI and GPS IWV of $(-0.7 \pm 1.1) \%)$. However, OMI, SCIAMACHY and AIRS show higher interquartile range (IQR) (which indicates lower precision) than the rest of satellite instruments. Both MODIS satellite instruments and SEVIRI products tend to slightly underestimate reference IWV data while GOME-2 exhibits a notable overestimation $(16.7 \pm 0.8 \%)$. All satellite instruments showed a tendency to reduce IWV extreme values: low IWV is overestimated while high IWV is underestimated. As for the influence of solar zenith angle (SZA), it can be observed that GOME-2 strongly overestimates the reference for high SZA values (by around $60 \%$ for SZA $60-80^{\circ}$ ). OMI shows, however, a high IQR for high SZA values. Both MODIS instruments show an increase in the pseudomedian of relative differences and IQR with SZA at daytime, with more stable values at night. Seasonal dependence is mainly due to the SZA and IWV typical values in each season. In general, in summer the tendency is to underestimate with low IQR (which happens when IWV is high and SZA is low), and in winter the trend is to overestimate with high IQR (which happens when IWV is low and SZA is high). SCIAMACHY shows a high pseudomedian in summer and autumn, and lower in winter and spring. It must be noted that GOME-2 shows a higher overestimation and OMI shows a higher IQR than other satellite instruments in winter and autumn. The influence of clouds was also studied, showing an increase of IQR as cloudiness increases in all satellites. Pseudomedian also worsens as cloudiness increases, generally.
\end{abstract}

\section{Introduction}

Water vapor plays a crucial role in Earth's radiative balance, since it is the main absorber of the infrared radiation emitted from Earth's surface, and therefore responsible for air heating in the low layers. Regarding energy transport, water vapor's latent heat is a very effective mechanism. Water is evaporated at low latitudes, and water vapor is transported to higher latitudes where condensation releases high

\footnotetext{
* Corresponding author.

E-mail address: javier_vm@unex.es (J. Vaquero-Martínez).
} 
Table 1

Summary with main characteristics of the instruments used.

\begin{tabular}{|c|c|c|c|c|c|c|c|}
\hline Satellite & Algorithm & Pixel size & $\lambda$ range & Period & Passing freq. & Cloud filter? & Cloud info? \\
\hline OMI & SAO OMH2O v. 1.0 Level 2 & $13 \mathrm{~km} \times 24 \mathrm{~km}$ & $430-480 \mathrm{~nm}$ & Once a day & 2007-2009 & Yes & Not available \\
\hline SEVIRI & SPhR-PGE13 v2.0 & $3 \mathrm{~km} \times 3 \mathrm{~km}$ & Around $6.7 \mu m$ & 2008-2012 & $15-30 \mathrm{~min}$ & No & No \\
\hline SCIAMACHY & AMC-DOAS & $30 \mathrm{~km} \times 60 \mathrm{~km}$ & Around $700 \mathrm{~nm}$ & 2007-(April)2012 & $\begin{array}{l}\text { Around once every } \\
6 \text { days }\end{array}$ & Indirectly & No \\
\hline GOME-2 & GDP v. 4.6 & $80 \mathrm{~km} \times 40 \mathrm{~km}$ & $614-684 \mathrm{~nm}$ & 2007-2012 & Twice every three days & Yes & Yes \\
\hline MODIS & & $5 \mathrm{~km} \times 5 \mathrm{~km}$ & $\begin{array}{l}\text { NIR(nighttime) IR } \\
\text { (daytime) }\end{array}$ & 2007-2012 & $1-2$ per day & Yes & Yes \\
\hline AIRS & $\begin{array}{l}\text { AIRS/Aqua L2 St. Phys. Ret. (AIRS- } \\
\text { only) }\end{array}$ & $13.5 \mathrm{~km}$ & IR & 2007-2012 & $1-2$ times a day & Yes & Yes \\
\hline
\end{tabular}

amounts of heat (Myhre et al., 2013). Water vapor is the most important natural greenhouse gas, indispensable for life on Earth. Its hydroxyl $(\mathrm{H}-\mathrm{O})$ bond allows absorption in the infrared region. Moreover, it involves a positive feedback loop in climate change, according to general circulation models (Colman, 2003). If the temperature of atmosphere rises, air can hold more water vapor, as the saturation vapor pressure increases with temperature. This further increases the greenhouse effect, warming the atmosphere.

Quality data for integrated water vapor (IWV) are critical for improving current understanding of the effect of water vapor in the climate system. Nevertheless, monitoring water vapor has some difficulties. First, its high variability, both temporally and spatially. Water vapor exhibits both an annual cycle (Ortiz de Galisteo et al., 2014) and a diurnal one (Ortiz de Galisteo et al., 2011). Second, the challenge to obtain data under a wide range of sky conditions. Additionally, groundbased water vapor data are particularly scarce over polar and oceanic regions. As a result, satellite measurements are necessary to improve the spatial coverage.

There are numerous techniques for measuring IWV, both from ground and from space. Among ground-based measurements there are microwave radiometers (Turner et al., 2007), sun-photometers (Ichoku et al., 2002), lunar-photometers (Barreto et al., 2013), star-photometers (Pérez-Ramírez et al., 2012), Lidar (Turner et al., 2002), GPS system (Ortiz de Galisteo et al., 2011), and radio-sounding (Torres et al., 2010). Space measurements are performed using satellites which collect information from different parts of the electromagnetic spectrum: microwave (Jones et al., 2009), visible (Román et al., 2015; Wang et al., 2014), near-infra-red (Grossi et al., 2015) and infra-red (Bennouna et al., 2013).

Radiosonde and GPS are the most powerful techniques to measure IWV. However, temporal coverage of radiosonde is very limited (generally one or two measurements a day). Because of this, GPS is used in this study as reference to validate satellite IWV data. GPS ground-based retrieval of water vapor has been studied broadly, as in Ortiz de Galisteo et al. (2010), for GPS antenna corrections, and in Pany et al. (2001) and De Haan et al. (2002), where GPS data were compared with a numerical model. One of the key features of GPS IWV retrieval is its independence of meteorological events (Rohm et al., 2014), such as cloudiness or precipitation, along with its high temporal resolution, as mentioned above.

Nevertheless, the coverage of GPS stations is currently not sufficient to represent the high spatial variability of water vapor. Some applications, such as weather forecasts and climate studies, need global data with higher spatial resolution, and therefore satellite observations are useful in those cases. However, satellite retrievals have two main problems (Diedrich et al., 2016). On the one hand, if they are low Earth orbiting satellites, they do not adequately sample the diurnal cycle (only one or two measurements a day). On the other hand, if visible or NIR spectra are used, the opacity of clouds makes the measurements under cloudy-sky condition unreliable (Diedrich et al., 2016).

In this work, a detailed inter-comparison between IWV data from seven satellite instruments against reference GPS measurements is performed. The instruments are: Global Ozone Monitoring Instrument (GOME-2), Moderate-Resolution Imaging Spectroradiometer (MODIS) on the Terra and Aqua satellites, Ozone Monitoring Instrument (OMI), Spining Enhanced Visible and InfraRed Imager (SEVIRI), Atmospheric Infrared Sounder (AIRS), and Scanning Imaging Absorption Spectrometer for Atmospheric Chartography (SCIAMACHY). GOME-2 IWV data have been widely validated (Noël et al., 2008; Antón et al., 2015; Grossi et al., 2015; Román et al., 2015; Kalakoski et al., 2016), as well as MODIS water vapor products (Li et al., 2003; Gao and Li, 2008; Prasad and Singh, 2009; Bennouna et al., 2013; Chang et al., 2015; Ningombam et al., 2016; Vaquero-Martínez et al., 2017a). However, the validation of OMI IWV product has only been found in Wang et al. (2016a) and Vaquero-Martínez et al. (2017b), AIRS IWV products in Hagan et al. (2004), Rama Varma Raja et al. (2008), Milstein and Blackwell (2016), SCIAMACHY IWV products in Bovensmann et al. (1999), Noël et al. (2005), Schrijver et al. (2009), du Piesanie et al. (2013), and SEVIRI IWV products in (Hanssen et al., 2001; SchroedterHomscheidt et al., 2008).

To our knowledge, an intercomparison between seven satellite instruments against a common reference dataset has not been performed before. Therefore, the main goal of this article is to analyze the differences and similarities in the performance of different satellite IWV products in order to improve the understanding of the quality of satellite IWV observations.

\section{Instruments and data}

\subsection{Satellite instruments and their IWV products}

Some of the main characteristics of the satellite instruments are summarized in Table 1. A more detailed description of the satellite instruments and their IWV products can be found in the following subsections.

\subsubsection{GOME-2}

GOME-2 (Callies et al., 2000) is an improved version of the GOME instrument, a medium-resolution UV-VIS-NIR spectrometer. The primary product of the GOME-2 satellite is the total atmospheric content of ozone and the vertical ozone profile. Additionally, it also provides information about other trace gases in the atmosphere, such as the total column amount of water vapor, sulphur dioxide, total and tropospheric nitrogen dioxide, tropospheric ozone and bromine oxide. Currently, there are two operational GOME-2 sensors on-board the MetOp-A and MetOp-B satellites. The default scan widths are $960 \mathrm{~km}$ and $1920 \mathrm{~km}$, enabling the combined GOME-2 sensors to cover Earth's surface in a daily basis with a ground pixel of $40 \mathrm{~km} \times 40 \mathrm{~km}$ (EUMETSAT, 2011).

The IWV data used in this work, obtained from GOME-2 MetOp-A, were derived from the GOME Data Processor (GDP, version 4.6) generated by the German Aerospace Center, Remote Sensing Technology Institute (DLR-IMF) in the framework of the EUMETSAT satellite Application Facility on Atmospheric Chemistry Monitoring (O3 M SAF) (Grossi et al., 2015). The period of study extends from 2007 to 2012. 
The retrieval method implemented in GDP is based on Differential Optical Absorption Spectrography (DOAS). This algorithm, described in detail in Wagner et al. (2006, 2003), consists of three steps:

1. DOAS fitting: water vapor, $\mathrm{O}_{2}$ and $\mathrm{O}_{4}$ absorptions are taken into account. $\mathrm{H}_{2} \mathrm{O}$ cross section is based on line-by-line computations using HITRAN $\mathrm{H}_{2} \mathrm{O}$ line parameter for a fixed temperature and pressure. The broadband filtering is improved by including three types of vegetation spectra, as well as a correction for the ring effect (see Wagner et al., 2009).

2. Non-linearity absorption correction: GOME-2 cannot spectrally resolve the water vapor (and oxygen) absorption bands, the water vapor slant column density is not linear with IWV, and a correction must be applied. The correction factors are obtained by means of the mathematical convolution of $\mathrm{H}_{2} \mathrm{O}$ spectrum with the instrument slit function. Such effect is more important for large $\mathrm{H}_{2} \mathrm{O}$ SCDs.

3. Vertical column density calculation: The corrected SCD must be converted to vertical column densities (VCDs) to make them geometry-independent. This is achieved by dividing SCD by a convenient air mass factor (AMF), which is derived from oxygen absorption. AMF is obtained dividing $\mathrm{O}_{2}$ SCD by the $\mathrm{O}_{2}$ VCD for a standard atmosphere. AMF for water vapor and oxygen is assumed to be similar, which can cause some systematic errors. $\mathrm{O}_{2} \mathrm{AMF}$ is expected to be larger than water vapor's, since $\mathrm{O}_{2}$ scale height is larger than $\mathrm{H}_{2} \mathrm{O}$ scale height. In order to correct this, a look-up table with correction factors is applied, which depends on SZA, line of sight angle, relative azimuth and surface albedo. The correction factors are calculated through radiative transfer calculations.

The fitting algorithm uses the wavelength region between 614 and $683 \mathrm{~nm}$, where the spectral resolution is about $0.54 \mathrm{~nm}$. The main advantages of IWV products from GOME-2 are their independence of external calibration sources and their accuracy both over land and over ocean, and the lack of assumptions on atmospheric pressure, temperature, radiative transfer, or other a-priori information.

\subsubsection{MODIS-Terra and MODIS-Aqua}

MODIS is on-board Terra and Aqua satellite platforms (King et al., 1992). Terra's orbit around the Earth is scheduled to overpass the equator from north to south in the morning, while Aqua passes from south to north over the equator in the afternoon. They cover the whole planet in 1-2 days. Its swath width is $2330 \mathrm{~km}$.

MODIS has 36 spectral bands, some of which $(890-920 \mathrm{~nm}$, 931-941 $\mathrm{nm}$ and $915-965 \mathrm{~nm}$ ) are related to atmospheric water vapor. These bands have a spatial resolution of $1 \mathrm{~km}$, but Level 2 moisture profiles are binned using $5 \times 5$ pixels. Thus, the resolution of the IWV product is $5 \mathrm{~km} \times 5 \mathrm{~km}$. The water vapor product is generated for both daytime (using NIR bands) and night (using IR bands).

For daytime, NIR bands (channels 2, 5, 17, 18, 19) are used (solar radiation reflected by Earth + atmosphere). The NIR algorithm uses 2channel and 3-channel rationing techniques. Look-up tables are generated with values of these ratios, calculated from radiative transfer programs. The total amount of water vapor can be transformed into IWV by taking into account the solar and observational geometries. If clouds are present, other channels in the range of $0.8-2.5 \mu \mathrm{m}$ region are used, since they contain information on absorptions due to water vapor above and within clouds. The algorithm is thoroughly explained in Gao and Kaufman (1992), Gao and Li (2008).

For nighttime, IR bands are used (radiation emitted by Earth + atmosphere). The algorithm employs a statistical retrieval with an option for a subsequent nonlinear physical retrieval (Seemann et al., 2003). The algorithm calculates MODIS infrared band radiances from a dataset of radiosonde observations, in order to associate computed radiances with atmospheric profiles. The MODIS atmospheric watervapor product is then estimated from the total column water vapor, integrating MODIS infrared retrievals of atmospheric moisture profiles in clear-sky scenes.

The data are included in the water vapor product (MOD05_L2 and MYD05_L2) collection 6. It is, however, obtained from the MODIS Atmospheric Profile (MOD07 and MYD07) Collection 6 product, simply added to product MOD05 for convenience.

\subsubsection{OMI}

OMI (Levelt et al., 2006) was developed by the Netherland's Agency for Aerospace Programs (NIVR) and the Finnish Meteorological Institute (FMI) to the EOS Aura mission. It is on-board NASA's Earth Observing System (EOS) Aura satellite platform. Aura has a Sun-synchronous polar orbit, which allows OMI to sample the whole planet daily at 1330 local time (LT). The nominal OMI pixel size is $13 \mathrm{~km} \times$ $24 \mathrm{~km}$ at nadir.

The OMI IWV data used in this study are the first version of the Smithsonian Astrophysical Observatory (SAO) OMH2O level 2 retrieval which uses the algorithm presented in Wang et al. (2014). The algorithm uses a window of $430 \mathrm{~nm}-480 \mathrm{~nm}$, and it follows three steps: (1) direct fitting of Slant Column Density (SCD), using a semi-empirical model that considers several gases (water vapor, ozone, nitrogen dioxide, liquid water, and more), as well as some effects (the ring effect, wavelength shift, and more); (2) SCD conversion to Vertical Column Density (VCD) using the Air Mass factor (AMF), which is calculated using radiative transfer calculations in look-up tables at $442 \mathrm{~nm}$, and (3) conversion of VCD to IWV by a conversion of units.

Following the guidelines from Wang et al. (2014), some restrictions have been applied to the $\mathrm{OMH} 2 \mathrm{O}$ product to assure its quality. Cloud fraction has to be below 0.1, cloud top pressure over $500 \mathrm{HPa}$, AMF greater than 0.75 , retrieval root mean square (RMS) value for the fitting Slant Column Density lower than 0.005, maindataqualityflag flag equal to 0 . Pixels affected by the row anomaly (see Wang et al., 2014) have been rejected as well.

\subsubsection{SEVIRI}

Meteosat are a series of geostationary satellites operated by EUMETSAT. Meteosat Satellites are equipped with SEVIRI, which counts with 7 IR bands in the range $6.2-13.4 \mu \mathrm{m}$. The retrieval algorithm uses the bands WV6.2, WV7.3, IR10.8, IR12.0 and IR13.4, where the first two are bands of strong absorption by water vapor. The retrieval process deals with obtaining the profile of temperature and humidity from infrared brightness temperature observations, using an inversion technique, i.e. trying to find an atmospheric profile that would reproduce the observations. The solution to this problem is not generally unique, so a background profile is used as a constraint. This background profile is obtained from a short range forecast model, and it is slowly varied until its radiative properties fit the observations. The algorithm of retrieval is detailed in AEMET and NWC SAF (2013).

One of the limitations of this algorithm is that its products are only available under clear conditions. In some cases, such as cirrus clouds or in the edge of clouds, NWCSAF/MSG Cloud Mask module might not detect clouds and the algorithm would try to estimate IWV over those pixels. However, the retrieval in those cases usually fails or needs a high number of iterations, which is detected by a quality flag. Moreover, mountain regions can exhibit large errors if there are differences between NWP topography, and the same can happen with temperature over very hot or cold pixels, where NWP first guess and the actual skin temperature can be quite different. Additionally, the effect of emissivity temporal variation is not handled, and fixed values from IREMIS monthly datasets have been used.

As Meteosat is geostationary, data are available with very high temporal resolution. The product temporal resolution is $30 \mathrm{~min}$. Only the temporally closer datum to every GPS datum was selected. Its spatial resolution is $3 \mathrm{~km} \times 3 \mathrm{~km}$. SEVIRI IWV resolution is around $0.58 \mathrm{~mm}$. 


\subsubsection{SCIAMACHY}

SCIAMACHY (Bovensmann et al., 1999) is an instrument on-board the Envisat satellite. It was operational from March 2002 to April 2012. Thus, our study period in this work for SCIAMACHY is from 2007 until April 2012. Envisat orbited the Earth in a sun-synchronous orbit, overpassing the equator at $10.00 \mathrm{~h} \mathrm{LT}$ every day. It sampled the whole planet in 6 days in nadir mode. SCIAMACHY's ground pixel size is typically $60 \mathrm{~km} \times 30 \mathrm{~km}$.

The retrieval algorithm for SCIAMACHY data is based on the Air Mass Corrected Differential Absorption Spectroscopy (AMC-DOAS) method (Noël et al., 2004). This method allows to obtain the IWV from measurements in the spectral region around $700 \mathrm{~nm}$. The use of visible light makes the method only applicable to daytime and (almost) cloudfree scenes. One of the main advantages of AMC-DOAS is that it provides a completely independent data set, since the IWV products do not depend on external information.

AMC-DOAS algorithm is based on a modification of DOAS approach. In this modification, the saturation effects from highly structured differential spectral features that are not resolved by the instruments are accounted for. Moreover, $\mathrm{O}_{2}$ absorption features are fitted in combination with $\mathrm{H}_{2} \mathrm{O}$ to derive a correction for the Air Mass Factor (AMF). This correction tries to compensate the lack of information on background and topographic characteristics, and represents how similar the atmospheric conditions and the conditions in the model calculations are. For example, if the correction were 1 it would indicate a perfect match (the correction ranges from 0 to 1 ). Therefore, the correction factor also contains information about the quality of the retrieved IWV.

In order to assess the quality of data, SCIAMACHY data are filtered using the following criteria: local SZA below $88^{\circ}$ and AMF correction greater than 0.8. There is no specific cloud filter applied, but the AMF correction criterion takes out most of the cloudy scenes.

\subsubsection{AIRS}

AIRS (Aumann et al., 2003) is a high-spectral resolution infrared sounder aboard NASA's Aqua satellite platform. It surpasses the Iberian Peninsula 1-2 times a day. The IR bands used in the retrieval process have a spatial resolution of $13 \mathrm{~km}$.

The AIRS products used for this work were AIRS/Aqua L2 Standard Physical Retrieval (AIRS-only) V6. This product has a quality flag for IWV data. The algorithm used in the retrieval (Barnet and Nedis, 2007) has been designed so that all data products simultaneously satisfy the measurements in a least-squares sense. The Standard Product includes measurements of cloud and surface properties, profiles of retrieved temperature, water vapor, ozone, and a flag for cloud ice or water, as well as the errors associated with these quantities.

Observed radiances are passed through a neural network to obtain the atmospheric state, from which cloud parameters are retrieved and then a cloud clearing is performed to obtain cloud-cleared radiances. This process is done iteratively twice and then a first physical retrieval algorithm is applied, with the cloud-cleared radiances and the atmospheric states as inputs. Then, a new cloud parameter retrieval process is performed and another cloud clearing as well, with new cloudcleared radiances as output. Then, the type of surface is chosen by the algorithm, obtaining the final state of the whole set of atmospheric variables. For more details, see Olsen et al. (2013a,b).

Data with quality flag 2 are rejected in this work, while data with flag 1 or 0 are accepted. Quality flag 2 data are not recommended for use, while data with quality flag 1 may be used for statistical climate studies. Data with quality flag 0 , recommended for comparison with in situ measurements, would be more suitable, but the number of datapoints was scarce for the purpose of this work. The bands for water vapor retrieval are $938 \mathrm{~cm}^{-1}, \quad 1310-1606 \mathrm{~cm}^{-1}$ and $2607-2657 \mathrm{~cm}^{-1}$, respectively.

Data were downloaded from AIRS Science Team/Joao Texeira (2013), AIRS/Aqua L2 Standard Physical Retrieval (AIRS-only) V006, version 006, Greenbelt, MD, USA, Goddard Earth Sciences Data and
Information Services Center (GES DISC), Accessed September 2016, 10.5067/AQUA/AIRS/DATA202.

\subsection{GPS IWV data}

The method to obtain IWV from GPS measurements is briefly described in this paper. A more detailed explanation can be found in Bevis et al. (1992).

The satellites that form the constellation of GPS communicate through L-band microwave radiation with ground-based receivers. Usually, the time spent by the signal in reaching the receiver is used to calculate the distance between the satellites and the receiver. However, several corrections need to be accounted for. In particular, the troposphere produces a delay in the signal, which is usually called Slant Tropospheric Delay (STD). It can be converted to the Zenith Tropospheric Delay (ZTD) through the so-called mapping functions. In this case, Niell's mapping function (Niell, 2000) was used.

$\mathrm{ZTD}=\frac{\mathrm{STD}}{m(E)}$

Once the ZTD is obtained, it can be separated in two different contributions: the Zenith Hydrostatic Delay (ZHD) and Zenith Wet Delay (ZWD).

$\mathrm{ZTD}=\mathrm{ZHD}+\mathrm{ZWD}$

The former is due to the tropospheric gases, while water vapor is responsible for the latter. The ZHD can be modeled and removed if surface temperature and atmospheric pressure at the station are known. The quality of these meteorological data is important to minimize errors in the final product (Wang et al., 2016c). IWV is obtained from the remaining ZWD. The relation between ZWD and IWV is linear,

$\mathrm{IWV}=\Pi \cdot \mathrm{ZWD}$

The constant $\Pi$ depends on the water vapor - weighted mean temperature (Wang et al., 2016b), which can be derived from surface temperature.

The GPS IWV data used in this work have been obtained from ground-based GPS measurements of the zenith total delay (ZTD). The tropospheric products were provided by the Spanish Geographic Institute "Instituto Geográfico Nacional", which is a local analysis center of the European Reference Frame (EUREF). The analysis is performed using Bernese 5.0 software for GNSS data processing. Two steps are required: in a first step, the coordinates of the stations are obtained with high precision, and in the second step, ZTD is obtained. The method is based on the resolution of the equation for double differences of phase (Leick, 1995; Rohm et al., 2014), which uses a network of ground-based receiver stations and differences of time in reaching the signal between different stations of the network to calculate the stations positions and other delays and sources of error.

As is described above, once we get the ZTD, two variables are needed to model ZHD: temperature and pressure at the location of the GPS stations. This information was provided by the Spanish Meteorological State Agency (AEMet). AEMet stations are not necessarily in the same exact location where the GPS receiver is located. However, the stations are as close as possible, usually in the same region. In the case of altitude difference, temperature was corrected by assuming a vertical gradient of temperature of $6.5 \mathrm{~K}$. Data are interpolated to the time of the GPS measurements. In the case of temperature, data were interpolated linearly. As for pressure, the barometric tide was taken into account to interpolate.

IWV data at the nine GPS stations were available for this work from 2007 to 2012. These GPS data, which have a temporal resolution of one hour, have been used to perform other validation exercises on satellite IWV data (Román et al., 2015; Bennouna et al., 2013; VaqueroMartínez et al., 2017a; Vaquero-Martínez et al., 2017b).

The stations selected for this research were located at the interior of 
Table 2

Characteristics of the GPS stations.

\begin{tabular}{llll}
\hline Station & Acronym & Latitude & Longitude \\
\hline & & $\left({ }^{\circ} \mathrm{N}\right)$ & $\left({ }^{\circ} \mathrm{E}\right)$ \\
Córdoba & coba & 37.92 & -4.72 \\
León & leon & 42.59 & -5.65 \\
Logroño & rioj & 42.46 & -2.5 \\
Salamanca & sala & 40.95 & -5.5 \\
Sonseca & sons & 39.68 & -3.96 \\
Teruel & teru & 40.35 & -1.12 \\
Valladolid & vala & 41.70 & -4.71 \\
Villafranca & vill & 40.44 & -3.95 \\
Cáceres & cace & 39.48 & -6.34 \\
\hline
\end{tabular}

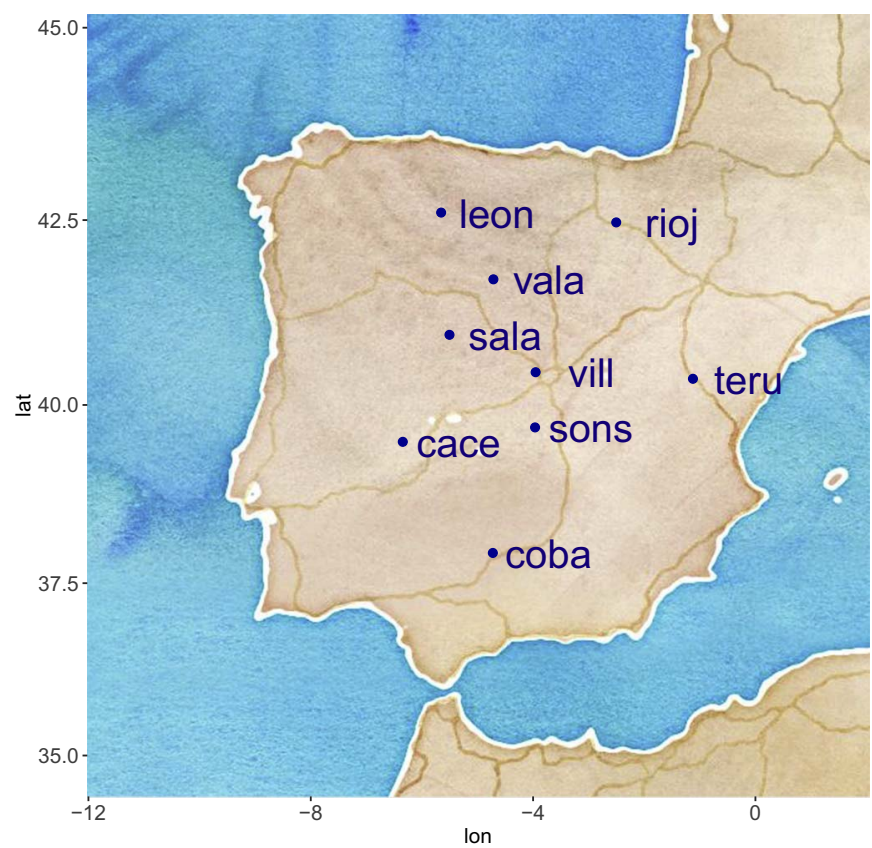

Fig. 1. Location of the nine stations selected.

the Iberian Peninsula. Coastal stations were rejected in order to avoid possible influences from error caused by sea or mixed sea-land pixels in satellite observations. Table 2 lists information for the nine stations selected and the map in Fig. 1 shows their locations in the Iberian Peninsula.

\section{Methodology}

\subsection{Collocation and comparison criteria}

Two different criteria were followed for spatial collocation. The first criterion was to take the pixel whose center was the closest to the ground-based GPS station. The second criterion was to average the closest pixels (those within $0.25^{\circ} \times 0.25^{\circ}$ distance to the ground-based GPS station). The first criterion was used for the collocation between GOME-2 and GPS, between MODIS-Terra and GPS, and SEVIRI and GPS.

The temporal criterion followed was to match GPS and satellite IWV values whose temporal difference was the closest. In all cases such difference had to be below $30 \mathrm{~min}$.

Satellite data under cloudy-sky conditions (cloud fraction given by each satellite algorithm larger than zero) have been rejected for all analyses, except for the study of cloud dependence (see Section 4.5), where all sky conditions were considered for those satellite datasets that provide information on cloudiness (i.e. GOME-2, MODIS-Terra and MODIS-Aqua, and AIRS).

\subsection{Statistical analysis}

Once the temporal and spatial match between the satellite and the GPS data is achieved, there is a dataset for each satellite, where every row has a satellite IWV value, a GPS IWV value, the location (station), and other columns with additional information, such as the date and time, SZA or cloud fraction (CF). The relative differences (Eq. (4)) studied in this work are calculated as:

$\delta_{i, s}=100 \cdot \frac{w_{i, s}^{\mathrm{sat}}-w_{i, s}^{\mathrm{GPS}}}{w_{i, s}^{\mathrm{GPS}}}$

where the index $s$ denotes a satellite, the index $i$ represents a fixed location and time and $w$ is the IWV measurement by the satellite (sat) or GPS.

The distribution of the satellite-GPS differences is analyzed for each ground-based station using several variables. First, two indices are calculated, the pseudomedian and the interquartile range (IQR). The pseudomedian is obtained using the Wilcoxon signed rank test with continuity correction (Wilcoxon, 1946). The pseudomedian is defined as the median of all the midpoints of pairs of observations, which agrees with the median if the dataset is symmetric. The pseudomedian of the relative differences provides information about the accuracy of the satellite data, while IQR reports about their precision. Pseudomedian has been chosen over median as index because it is a better estimator when the distribution is asymmetric, which is typically the case for $\delta$ distribution when applied to binned data.

Furthermore, a linear regression analysis between the GPS and the satellite data was performed in order to analyze their proportionality and similarity. Then, in order to study the dependence with certain variables, the two indices are applied to bins of data. The bin widths are $5^{\circ}$ for SZA, $5 \mathrm{~mm}$ for IWV and 0.10 for CF. Moreover, the seasonal dependence of relative differences was also analyzed in detail. Bins with less than 50 data points have been rejected. The dependence of distance satellite pixel - GPS ground-based station was not considered in this work, since Román et al. (2015) did not show an important impact in the satellite IWV data.

Table 3

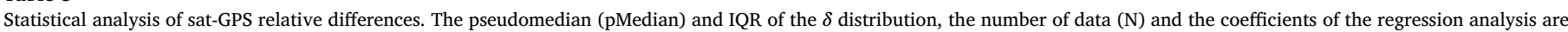
shown. $y_{0}$ column shows the intercept, $\mathrm{b}$ stands for the slope and R2 is Pearson's coefficient of determination. The numbers after \pm are the $95 \%$ confidence interval.

\begin{tabular}{|c|c|c|c|c|c|c|}
\hline Satellite & pMedian & IQR & $\mathrm{N}$ & $y_{0}$ & $b$ & $R^{2}$ \\
\hline & (\%) & $(\%)$ & & $(\mathrm{mm})$ & & \\
\hline OMI & $-0.7 \pm 1.1$ & 40.80 & 3895 & $2.65 \pm 0.28$ & $0.78 \pm 0.02$ & 0.63 \\
\hline SEVIRI & $-5.2 \pm 0.1$ & 33.31 & 187375 & $2.89 \pm 0.03$ & $0.690 \pm 0.002$ & 0.67 \\
\hline SCIAMACHY & $6.6 \pm 1.2$ & 45.72 & 2629 & $0.92 \pm 0.36$ & $0.96 \pm 0.02$ & 0.70 \\
\hline GOME-2 & $16.7 \pm 0.8$ & 32.58 & 4317 & $3.40 \pm 0.18$ & $0.88 \pm 0.01$ & 0.83 \\
\hline MODIS-Terra & $-0.9 \pm 0.5$ & 34.58 & 13651 & $1.01 \pm 0.14$ & $0.915 \pm 0.009$ & 0.74 \\
\hline MODIS-Aqua & $-3.4 \pm 0.4$ & 33.24 & 13581 & $0.99 \pm 0.14$ & $0.89 \pm 0.01$ & 0.71 \\
\hline AIRS & $2.0 \pm 1.8$ & 47.84 & 1832 & $3.05 \pm 0.41$ & $0.73 \pm 0.03$ & 0.56 \\
\hline
\end{tabular}




\section{Results and discussion}

\subsection{Statistical analysis}

Table 3 shows the pseudomedian and IQR of the satellite-GPS differences (Eq. (1)) for the seven satellite instruments. The results indicate that GOME-2, SCIAMACHY and AIRS highly overestimate, on average, the reference GPS data (positive pseudomedian values), while MODIS-Aqua, MODIS-Terra and SEVIRI have a small tendency to underestimate IWV (negative pseudomedian values). OMI pseudomedian, however, shows that there is no significant bias in OMI IWV with respect to reference GPS IWV. IQR is between 30\% and 35\% for GOME-2, both MODIS, and SEVIRI, while it is higher than $40 \%$ for OMI, SCIAMACHY and AIRS. The regression analyses performed for each satellite instrument show that the intercept $y_{0}$ is always positive and the slope $b$ is always lower than 1 . This suggests that satellite instruments tend to overestimate low IWV data, and underestimate high values. This result is in agreement with other studies (Rama Varma Raja et al., 2008; Bennouna et al., 2013; Antón et al., 2015; Román et al., 2015; Scheepmaker et al., 2015; Vaquero-Martínez et al., 2017b; VaqueroMartínez et al., 2017a). Correlation coefficient $R^{2}$ shows a fair agreement. The agreement is better for GOME- 2 and both MODIS instruments, and worse for AIRS. The validation of GOME-2 in Antón et al. (2015) against radiosonde showed a slightly better agreement $\left(R^{2}=0.95\right)$.

Fig. 2 presents a time series of each instrument (columns) and each station (rows). It can be observed that all satellites represent the seasonal variation of water vapor correctly. The lack of available data in some periods at some stations can be identified. For instance, teru station time series starts in 2009, because the GPS receiver in that station was not operative until 2009. Moreover, it can be observed that OMI data are only available in the period 2007-2009, as mentioned in Section 2.1. The different density of data-points is related to the satellite's passing frequency and the quality filters mentioned in Section 2.1. The differences between satellite and GPS IWV are also represented, showing that in all satellites these are approximately centered around $0 \mathrm{~mm}$.

\subsection{IWV dependence}

Fig. 3 shows the pseudomedian of the sat-GPS differences against reference (GPS) IWV data in bins of $5 \mathrm{~mm}$. The error bars are the $95 \%$ confidence interval in the Wilcoxon signed rank test with continuity correction. It can be seen that the behavior is similar in all satellite instruments: the pseudomedian is positive for the lowest IWV values in all of them, while satellite data tend to underestimate large IWV values. This is in agreement with the behavior observed in other studies (Antón et al., 2015; Vaquero-Martínez et al., 2017a,b). AIRS, GOME-2 and SEVIRI have the largest range of variation. Their pesudomedians reach almost $+40 \%$ (AIRS and SEVIRI) and $+60 \%$ (GOME-2) for low IWV values, while they decrease to $-30 \%$ (AIRS), $-25 \%$ (SEVIRI) and $-10 \%$ (GOME-2) in large IWV cases. Both MODIS instruments perform similarly, with Terra being slightly higher than Aqua. It can be noticed that SCIAMACHY and GOME-2 (whose retrieval algorithms use DOAS techniques) tend to slightly overestimate IWV for intermediate values ( $\sim 10-25 \mathrm{~mm}$ ), while the rest of satellites tend to underestimate IWV in this range of IWV values. The behavior of GOME-2 was also reported in Antón et al. (2015). In that work, GOME-2 showed discrepancies with reference radiosonde IWV data under $20 \%$ when data are grouped by similar SZA values. The strongest differences between Antón et al. (2015) and the present work are at low IWV values, suggesting that SZA might play an important role.

Regarding the precision statistical, IQR, Fig. 4 shows similar values for all satellite instruments except for OMI, which has much higher IQR for low IWV values (over 100\%, the rest being around 50\%). IQR decreases with increasing IWV in all cases, reaching values under $25 \%$ for high IWV. The satellite instrument with the lowest IQR in the whole range of IWV is GOME-2. The behavior of SCIAMACHY water vapor product is different. It keeps a high IQR for low and medium IWV (up to $25 \mathrm{~mm}$ approximately), only becoming lower than $20 \%$ at high IWV ( $>30 \mathrm{~mm}$ ). A similar pattern was reported in Noël et al. (2004) when ECMWF IWV data were used as reference.

\subsection{SZA dependence}

The influence of SZA on the pseudomedian is different for each satellite instrument, as seen in Fig. 5. OMI and GOME-2, which use visible radiation for IWV retrieval, show an increase of the

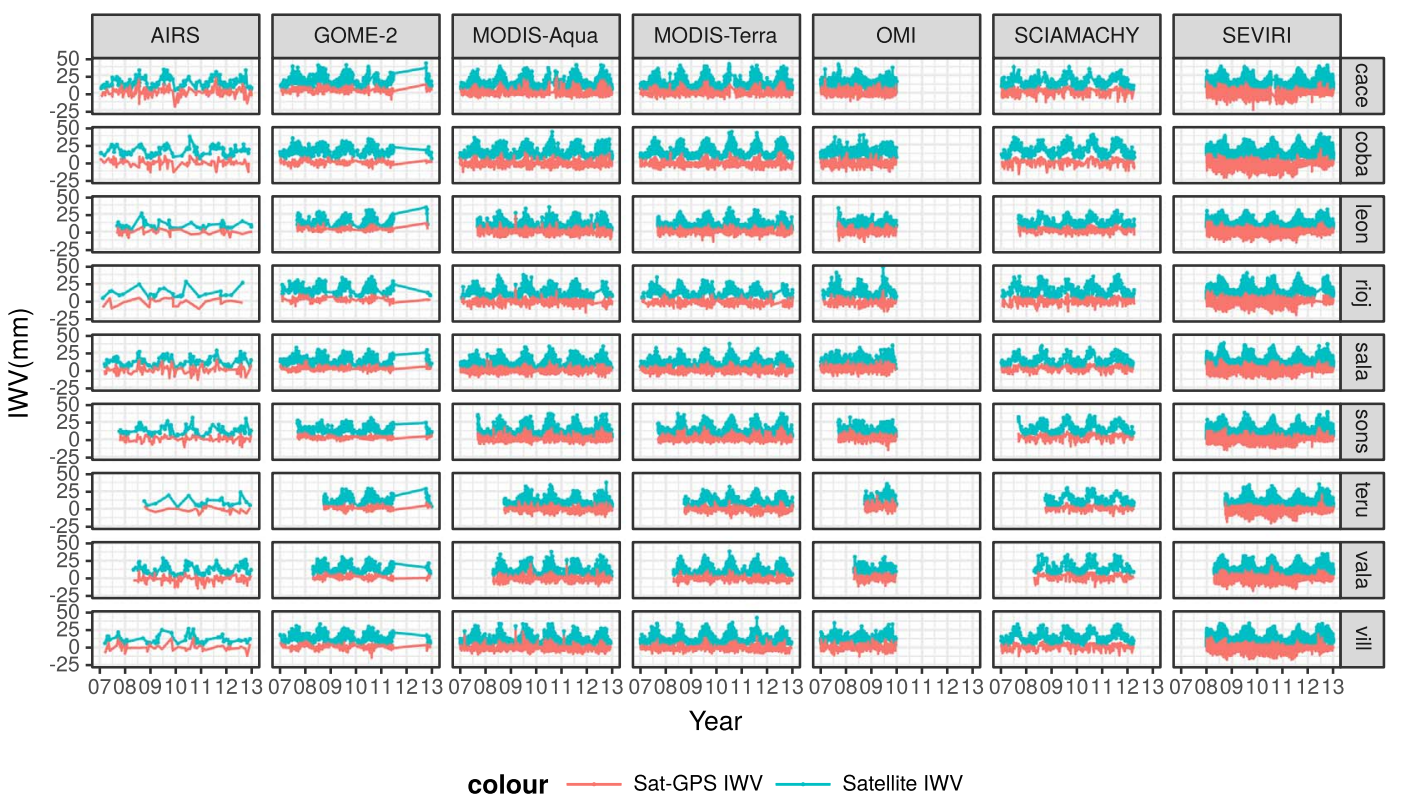

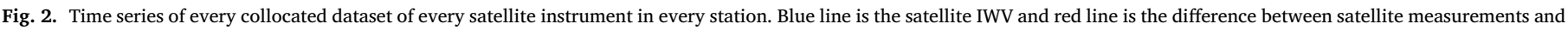
GPS data. 


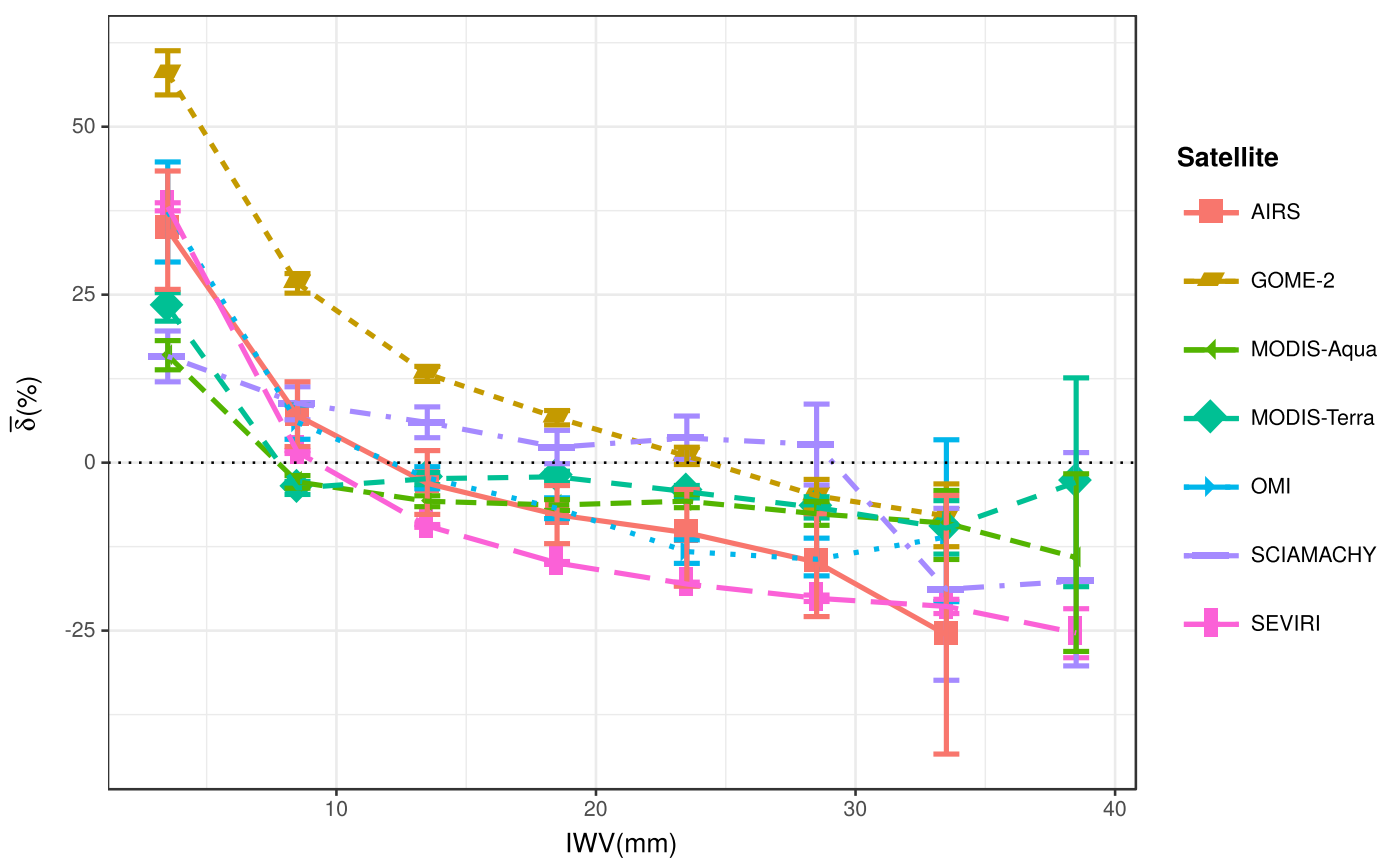

Fig. 3. Pseudomedian of sat-GPS relative differences against reference IWV (GPS). Error bars are the 95\% confidence interval in the Wilcoxon signed rank test.

pseudomedian with SZA. As SZA increases, the amount of IWV that the sunlight encounters increases. This could affect the correction factor used to calculate the air mass factor (AMF). In the case of OMI this change is very smooth, and could be explained by the correlation of SZA and IWV values (high IWV values occur when temperature is higher, which happens when SZA is low, and vice versa), as reported in Vaquero-Martínez et al. (2017b). The increase of the pseudomedian with SZA is specially strong in GOME-2, from very small values (under $5 \%$ ) for low SZA to very high values (around $80 \%$ ) for high SZA, as it has already been reported in the literature (Kalakoski et al., 2011; Antón et al., 2015; Román et al., 2015). By contrast, SCIAMACHY, which also uses visible radiation, shows the opposite behavior: a decrease of relative difference with increasing SZA. This can also be related to the quality of AMF correction being influenced by SZA in the retrieval algorithm used for this satellite instrument.

In the case of satellites that use IR radiation for IWV retrieval, i.e. the MODIS instruments (Terra and Aqua) and SEVIRI, the influence of SZA at daytime is similar to OMI. This fact suggests that the SZA dependence may be related to other variables that change with SZA (i.e. the amount of water vapor). In the case of AIRS, the pseudomedian seems to slightly decrease with SZA. Furthermore, when using IR radiation it is possible to make measurements in the nighttime. AIRS has a notably good performance at nighttime, with pseudomedian close to 0 for the whole nighttime range. The rest of the instruments have negative pseudomedian of the error at nighttime, above $-20 \%$. A strong discontinuity is observed between daytime and nighttime

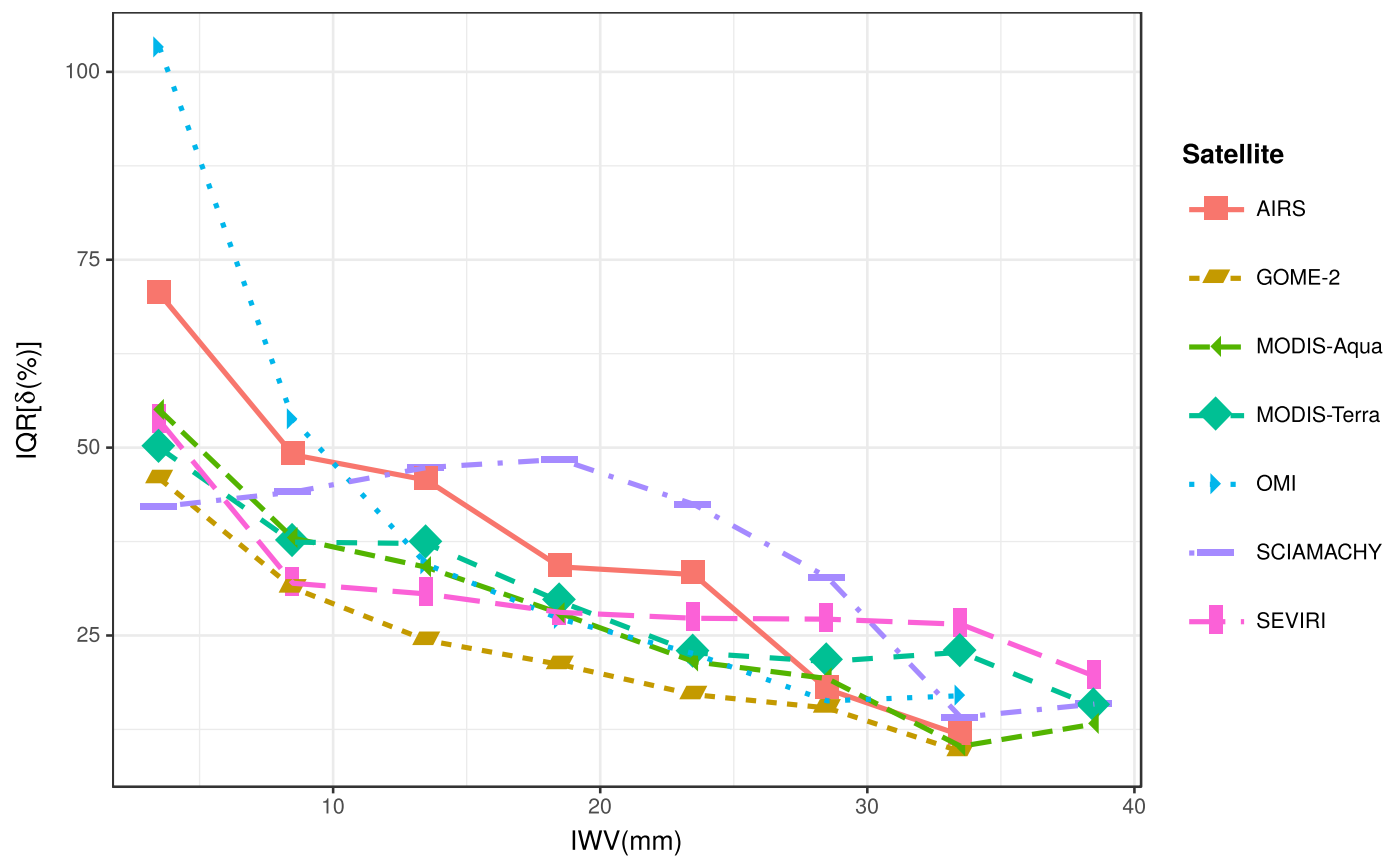

Fig. 4. IQR of sat-GPS relative differences against reference IWV (GPS). 


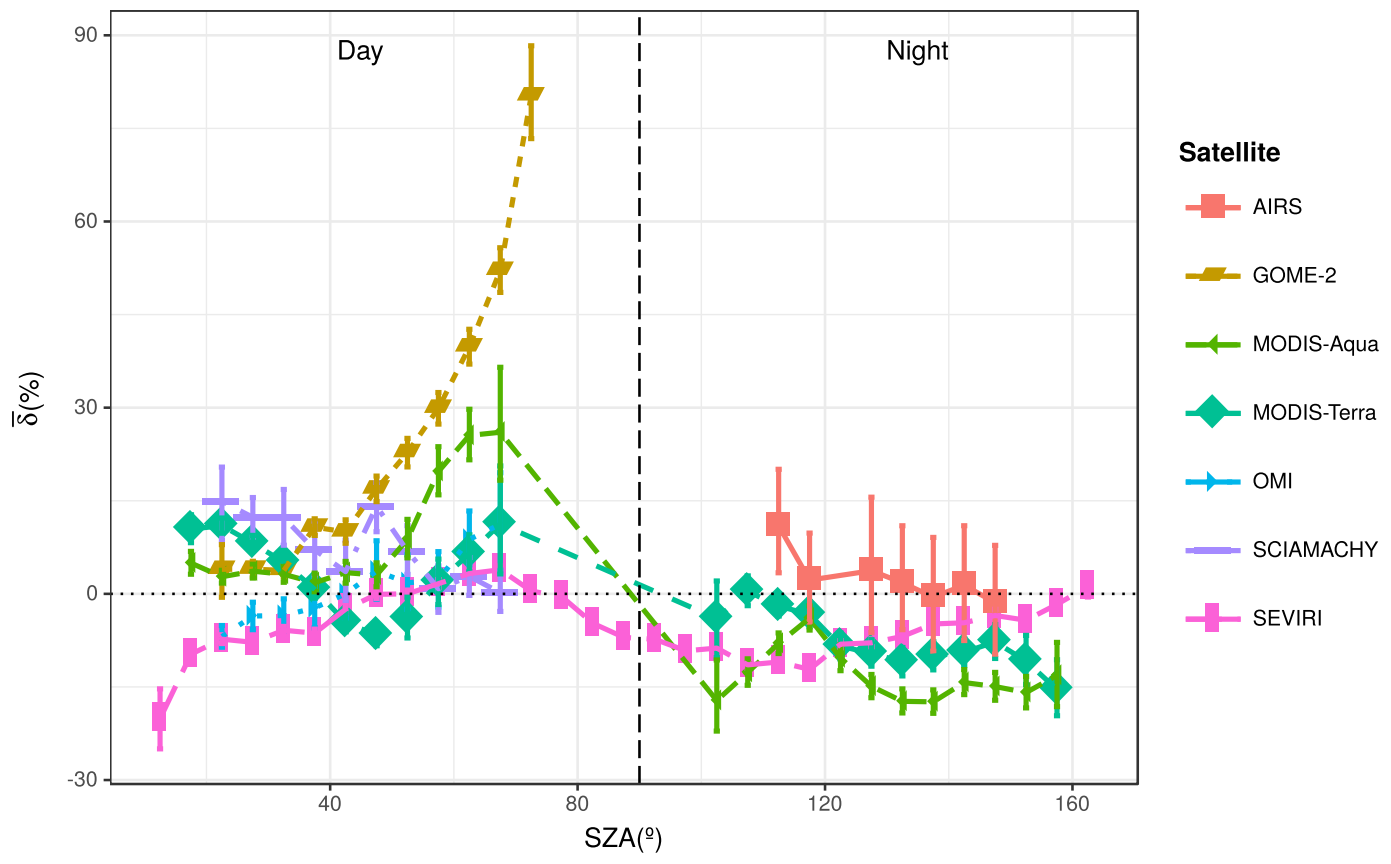

Fig. 5. Pseudomedian of sat-GPS relative differences against SZA.

measurements of MODIS. This is probably related to the fact that the IWV retrieval is different for daytime and nighttime. SEVIRI and AIRS, which use the same retrieval algorithm for both day and night, have a quite similar response in the whole SZA range.

The variation of IQR with SZA is plotted in Fig. 6. Again, OMI and GOME-2 behave similarly, but in this case GOME-2 performs better: its IQR ranges from under $20 \%$ for low SZA, to $50 \%$ for high SZA. By contrast, OMI IQR changes from $30 \%$ to more than $70 \%$, increasing with SZA. SCIAMACHY has a similar behavior as well, with higher values of IQR than OMI up to SZA $=50^{\circ}$, and between OMI and GOME2 from that SZA on. Both MODIS instruments have similar IQR compared to GOME-2. SEVIRI has a more stable IQR with SZA, always between $15 \%$ and $40 \%$. For nighttime, SEVIRI, MODIS-Aqua and
MODIS-Terra have similar IQR, slightly increasing with SZA. AIRS IQR at nighttime is clearly higher than the rest, while at daytime it is above $50 \%$. The increase of IQR with daytime SZA can be explained if we take into consideration the increasing corrections to obtain the proper AMF of water vapor. These corrections introduce noise in the measurements, which are stronger as the corrections are larger. Moreover, at high SZA IWV is usually lower, so the relative difference is higher for the same absolute difference.

\subsection{Seasonal dependence}

Satellite performance displays a dependence on the season of the year, related to the annual cycle of water vapor and SZA values. In

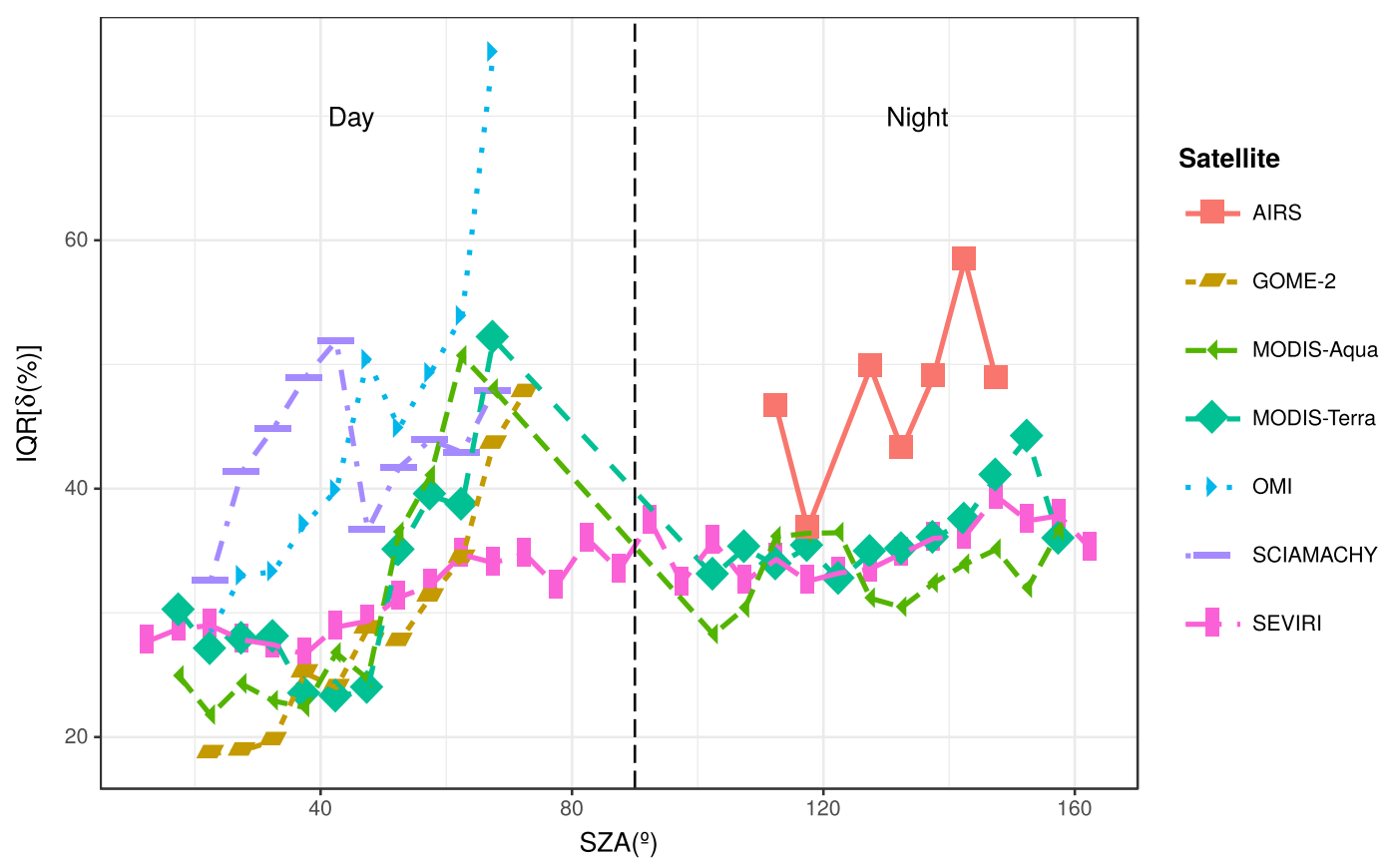

Fig. 6. IQR of sat-GPS relative differences against SZA. 


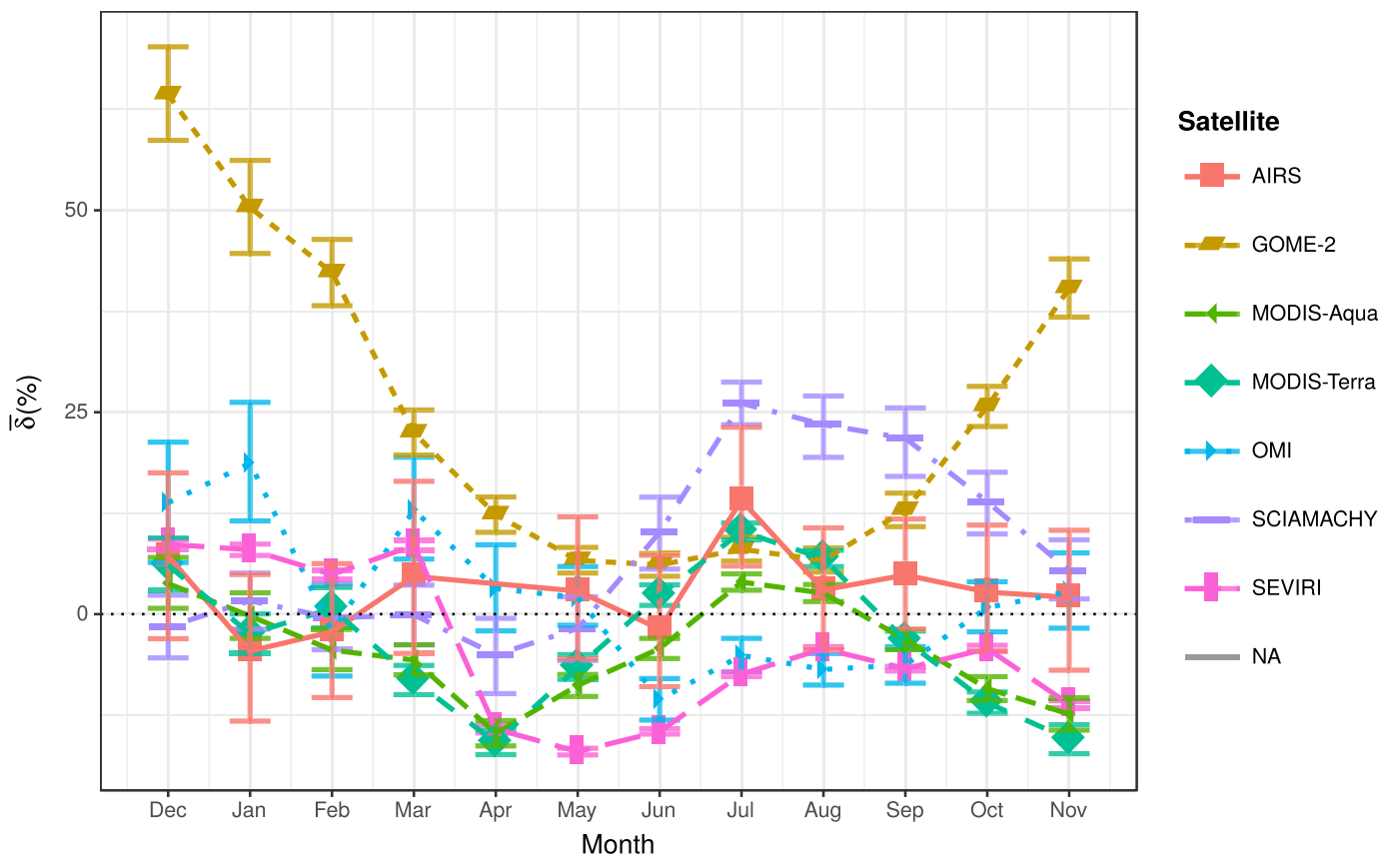

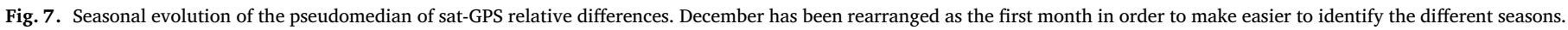

Fig. 7, the pseudomedian of the relative differences is shown in bins of one month. GOME-2 shows the strongest seasonal dependence, with pseudomedian values ranging from $+5 \%$ in summer to over $+50 \%$ in winter, which is probably connected to the strong dependence on SZA shown above. This is in agreement with Román et al. (2015), and shows higher pseudomedians than in Antón et al. (2015), where the reference instrument was radiosondes. The rest of the satellites have medians between $-25 \%$ and $+25 \%$. OMI has a similar behavior to GOME-2, with an overestimation (positive pseudomedian) in winter and a slight underestimation (negative pseudomedian) in summer, in agreement with Vaquero-Martínez et al. (2017b). However, both MODIS satellite instruments show overestimation in summer and underestimation almost the rest of the year (except for a slight overestimation in December). MODIS-Terra has slightly higher pseudomedian values in summer than MODIS-Aqua. Bennouna et al. (2013) showed that MODIS algorithm performed worse in winter. The reason for the discrepancy could be related to differences in datasets, such as the years used and the stations selected. If atmospheric conditions change, IWV will change too, and thus performance of the algorithm can be different. Moreover, SEVIRI underestimates from April to November and overestimates from December to March. AIRS is the closest to the zero line throughout the year. SCIAMACHY, however, has a special behavior: summer and autumn months are overestimated (up to 25\%), while winter and spring are slightly underestimated.

The seasonal dependence on the precision index can be seen in Fig. 8. All satellite instruments have a similar behavior: IQR is higher in winter than in summer. OMI has the higher IQR in winter and autumn, reaching more than $70 \%$ in December, while AIRS has IQR over $40 \%$ throughout the year, for almost all months. However, the rest of the satellite instruments have IQR from $20 \%$ to 55\%. GOME-2 data have the best performance except in winter, where all satellite instruments except OMI (higher IQR) perform similarly. This behavior can be related to the fact that in winter, IWV is smaller and thus the relative difference tends to be higher, as commented in Section 4.2. OMI behavior is in agreement with Vaquero-Martínez et al. (2017b).

\subsection{Cloudiness dependence}

The influence of cloudiness on the pseudomedian is represented in
Fig. 9 for those satellite instruments that provide information about cloudiness and were not filtered (AIRS, GOME-2, MODIS-Aqua and MODIS-Terra). In general, as CF increases the pseudomedian is further from the zero line: it can be below 0, underestimating the IWV (AIRS, GOME-2 and MODIS-Terra) or over 0, overestimating (MODIS-Aqua). The underestimation can be due to the so called shielding effect (Román et al., 2015; Kokhanovsky and Rozanov, 2008): clouds can "hide" the water vapor under them. The differences between MODIS-Aqua and MODIS-Terra could be related to their different passing times and the use of NIR radiation in daylight and IR during nighttime. At nighttime, the algorithm could confuse the presence of clouds with water vapor, causing the overestimation.

IQR, the precision index, is shown in Fig. 10. IQR computed for both MODIS data products increases as cloudiness increases, AIRS seems to have a stable value of IQR and GOME-2 shows a certain decrease of IQR as $\mathrm{CF}$ is higher. The reason for this could be that clouds introduce noise in the measurements, but if there are too many clouds, the shielding effect reduces the sensitivity to water vapor, decreasing the variability (IQR).

\section{Conclusions}

The analysis of the relative differences between satellite and GPS measurements has found some similarities and differences among the satellite measurements. In general, AIRS and OMI measurements are accurate (pesudomedian of the differences close to zero), but they are less precise than the rest of the satellites. Regarding precision the rest of the satellites perform similarly, but GOME-2 overestimates IWV while SEVIRI and both MODIS underestimate the measurements. Regression analysis showed that all satellites tend to homogenize water vapor: low IWV tends to be overestimated, while high IWV tends to be underestimated. This result was confirmed when studying the dependence of the relative differences on IWV data. The reason for this could be that spatial resolution of satellites is much lower than GPS ground-based stations, and thus IWV measurement is somehow averaged over the whole pixel. The precision index (IQR) showed that measurements are more precise as IWV increases. OMI precision is especially low (high IQR) at low IWV. IQR computed for SCIAMACHY data seems to be high up to $20 \mathrm{~mm}$, when IQR starts to decrease as IWV increases. 


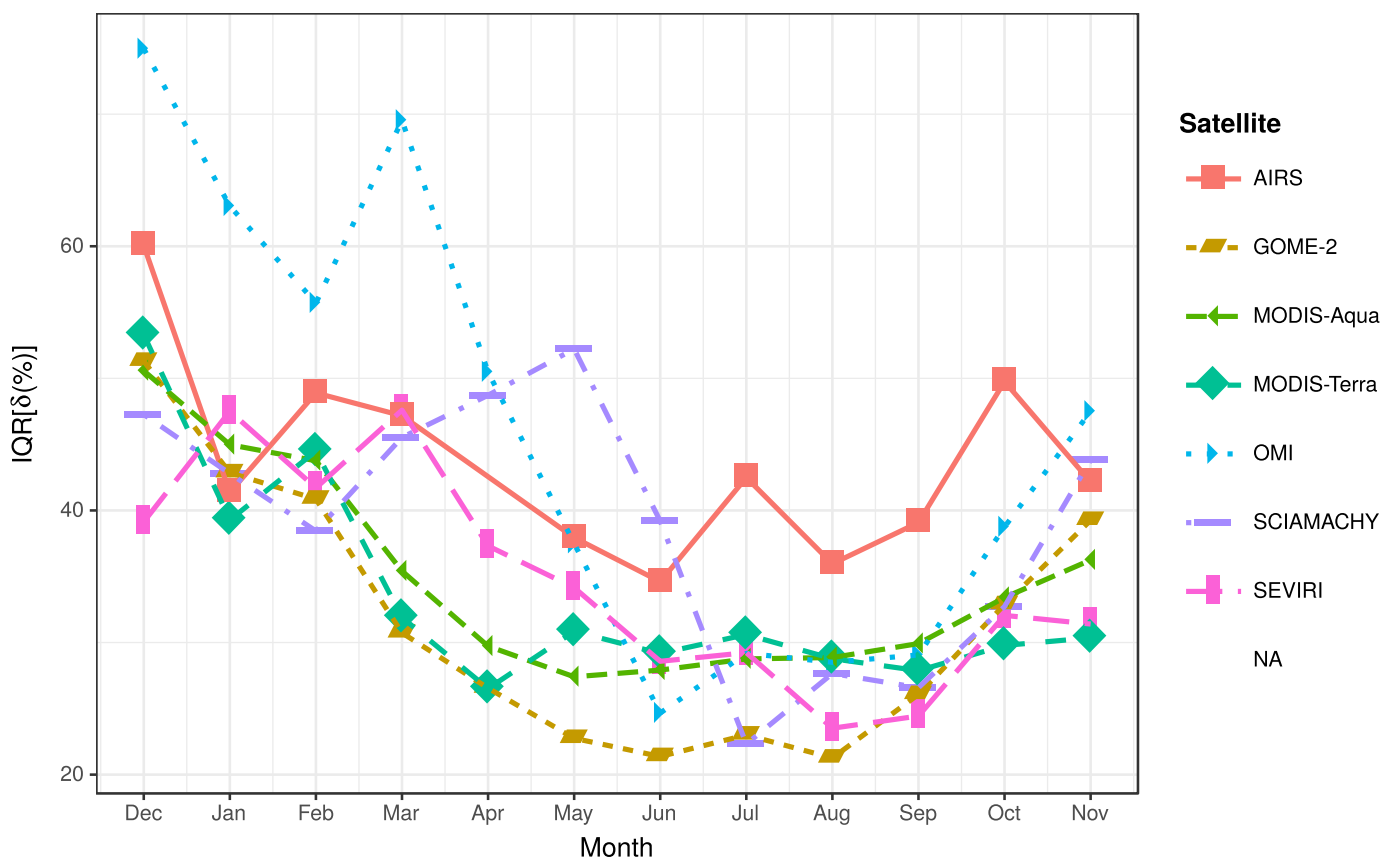

Fig. 8. Seasonal evolution of the IQR of sat-GPS relative differences. December has been rearranged as the first month in order to make easier to identify the different seasons.

The study on the influence of SZA on the relative differences showed that GOME-2 highly overestimates IWV at high SZA. There is a general tendency to overestimate for SZA between $60^{\circ}$ and $80^{\circ}$. OMI performs reasonably well although its precision quickly becomes lower (higher IQR) as SZA increases. SEVIRI has a quite stable IQR over the whole SZA range. Nighttime measurements are underestimated for all IR satellites (SEVIRI and MODIS-Terra and Aqua) except AIRS, which presents a good accuracy in nighttime.

The annual variations of the two indices are studied as well. The performance of all satellites is similar, with the following exceptions. GOME-2 shows a high overestimation during winter and autumn, probably the cause of its high overestimation in the general analysis. SCIAMACHY shows a high pseudomedian in summer and autumn, and lower in winter and spring. OMI shows very high IQR (low precision) in winter.

The influence of clouds is studied for those satellites that provide information about cloudiness. The presence of clouds increases the deviation of satellite IWV data with respect to the reference GPS measurements, whether overestimating (MODIS-Aqua) or underestimating (MODIS-Terra, GOME-2, AIRS). IQR generally increases or remains stable, except for GOME-2, which shows a slight decrease of IQR with CF.

Although satellite retrievals can provide good spatial coverage of IWV values, they still need improvements in order to reduce the notable differences and dependences observed when the satellite IWV products are compared against reference GPS data. This study indicates that

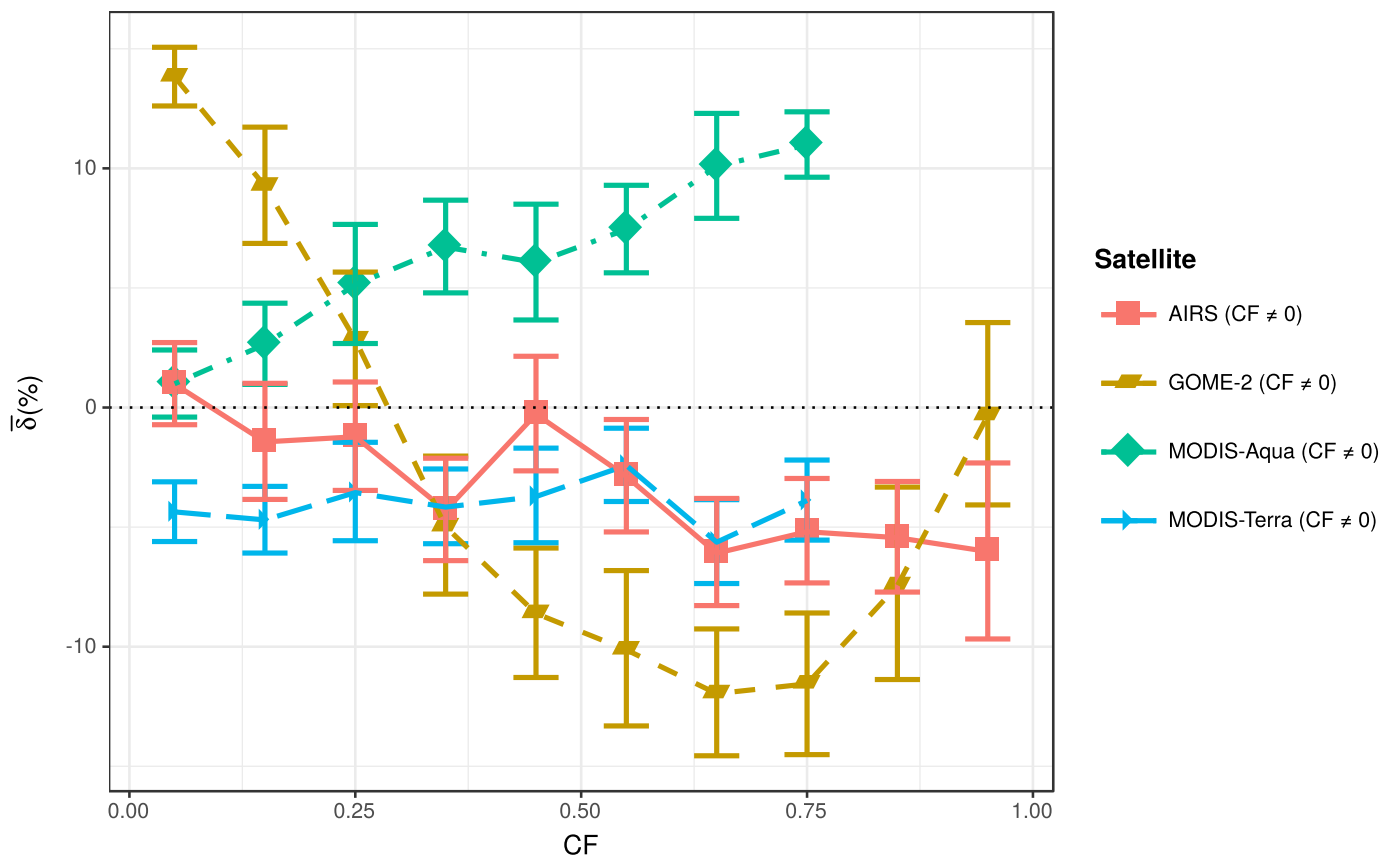

Fig. 9. Pseudomedian of sat-GPS relative differences against CF. 


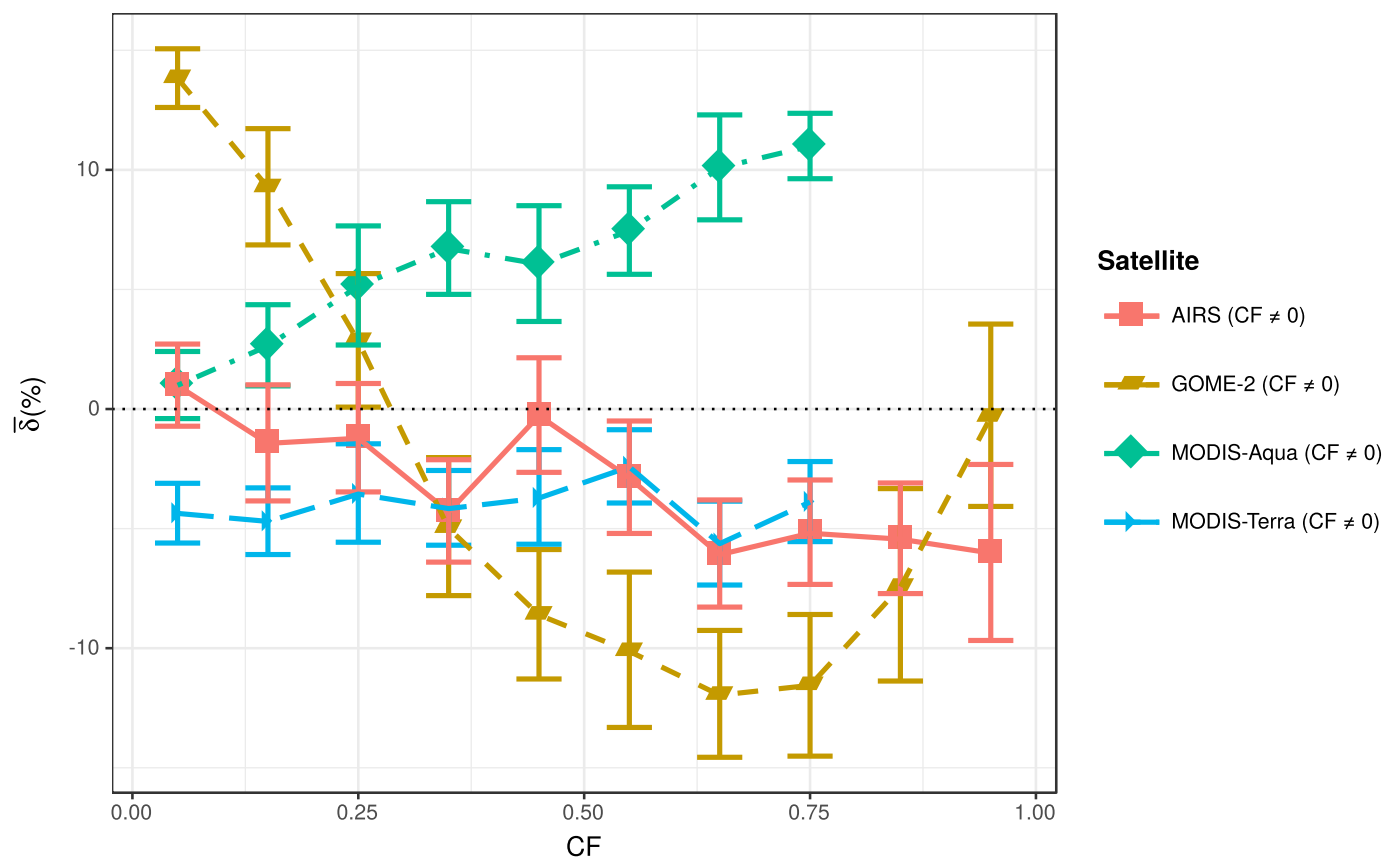

Fig. 10. IQR of sat-GPS relative differences against CF.

more work is needed to increase OMI precision and GOME-2 accuracy for low IWV, and to improve AIRS precision under all conditions.

\section{Acknowledgments}

This work was supported by the Spanish Ministry of Economy and Competitiveness through project CGL2014-56255-C2. Manuel Antón thanks Ministerio de Ciencia e Innovación and Fondo Social Europeo (RYC-2011-08345) for the award of a postdoctoral grant (Ramón y Cajal). Support from the Junta de Extremadura (Research Group Grants GR15137) is gratefully acknowledged. The GOME-2/MetOp-A products were generated at DLR under the auspices of the O3MSAF project funded by EUMETSAT and national contributions. The generation of SCIAMACHY data was supported by ESA, DLR Bonn and by the University of Bremen, Germany. Work at Universidad de Valladolid is supported by projects CMT2015-66742-R and MINECO VA100U14. Work at Universidad de Granada was supported by the Andalusia Regional Government (project P12-RNM-2409) and the Spanish Ministry of Economy and Competitiveness and FEDER funds under the projects CGL2013-45410-R, CGL2016-81092-R and "Juan de la CiervaFormación" program. Work at SAO is supported by NASA's Atmospheric Composition: Aura Science Team program (sponsor contract number NNX14AF56G). Work at Universidade de Évora is cofunded by the European Union through the European Regional Development Fund, included in the COMPETE 2020 (Operational Program Competitiveness and Internationalization) through the ICT project (UID/GEO/04683/2013) with the reference POCI-01-0145FEDER-007690.

\section{References}

AEMET,NWC, S.A.F., 2013. Algorithm Theoretical Basis Document for "SEVIRI Physical Retrieval Product" (SPhR-PGE13 v2.0). Technical Report.

Antón, M., Loyola, D., Román, R., Vömel, H., 2015. Validation of GOME-2/MetOp-A total water vapour column using reference radiosonde data from the GRUAN network. Atmos. Meas. Tech. 8, 1135-1145. http://dx.doi.org/10.5194/amt-8-1135-2015.

Aumann, H.H., Chahine, M.T., Gautier, C., Goldberg, M.D., Kalnay, E., Mcmillin, L.M., Revercomb, H., Rosenkranz, P.W., Smith, W.L., Staelin, D.H., Strow, L.L., Susskind, J., 2003. AIRS / AMSU / HSB on the Aqua mission : design, science objectives, data products, and processing systems. Processing 41, 253-264.

Barnet, C., Nedis, N., 2007. Airs-Team Retrieval for Core Products and Geophysical. Technical Report March.
Barreto, A., Cuevas, E., Damiri, B., Romero, P.M., Almansa, F., 2013. Column water vapor determination in night period with a lunar photometer prototype. Atmos. Meas. Tech. 6, 2159-2167. http://dx.doi.org/10.5194/amt-6-2159-2013.

Bennouna, Y.S., Torres, B., Cachorro, V.E., Ortiz de Galisteo, J.P., Toledano, C., 2013. The evaluation of the integrated water vapour annual cycle over the Iberian Peninsula from EOS-MODIS against different ground-based techniques. Q. J. R. Meteorol. Soc. 139, 1935-1956. http://dx.doi.org/10.1002/qj.2080.

Bevis, M., Businger, S., Herring, T. a., Rocken, C., Anthes, R. a., Ware, R.H., 1992. GPS meteorology: remote sensing of atmospheric water vapor using the Global Positioning System. J. Geophys. Res. 97, 15787-15801. http://dx.doi.org/10.1029/92JD01517.

Bovensmann, H., Burrows, J.P., Buchwitz, M., Frerick, J., Noël, S., Rozanov, V.V., Chance, K.V., Goede, a.P.H., 1999. SCIAMACHY: mission objectives and measurement modes. J. Atmos. Sci. 56, 127-150. http://dx.doi.org/10.1175/1520-0469(1999) $056<0127:$ SMOAMM $>2.0$. CO 2 .

Callies, J., Corpaccioli, E., Eisinger, M., Hahne, a., Lefebvre, a., 2000. GOME-2 - Metop's second-generation sensor for operational ozone monitoring. ESA Bull. Eur. Space Agency 102, 28-36.

Chang, L., Gao, G., Jin, S., He, X., Xiao, R., Guo, L., 2015. Calibration and evaluation of precipitable water vapor from Modis infrared observations at night. IEEE Trans. Geosci. Remote Sens. 53, 2612-2620. http://dx.doi.org/10.1109/TGRS.2014. 2363089.

Colman, R., 2003. A comparison of climate feedbacks in general circulation models. Clim. Dyn. 20, 865-873. http://dx.doi.org/10.1007/s00382-003-0310-z.

De Haan, S., Van Der Marel, H., Barlag, S., 2002. Comparison of GPS slant delay measurements to a numerical model: case study of a cold front passage. Phys. Chem. Earth 27, 317-322. http://dx.doi.org/10.1016/S1474-7065(02)00006-2.

Diedrich, H., Wittchen, F., Preusker, R., Fischer, J., 2016. Representativeness of total column water vapour retrievals from instruments on polar orbiting satellites. Atmos. Chem. Phys. Discuss. 16, 8331-8339. http://dx.doi.org/10.5194/acp-2016-99.

EUMETSAT, 2011. European Organisation for the Exploitation of Meteorological Satellites: GOME-2 Product Guide.

Gao, B.-C., Kaufman, Y.J., 1992. The MODIS near-IR water vapor algorithm product ID: MOD05 - total precipitable water. Algorithm Tech. Backgr. Doc. 1-25 URL: Biblioteca Digital SPRGao1992_ATBD.pdf.

Gao, B.C., Li, R.R., 2008. The time series of Terra and Aqua MODIS near-IR water vapor products. Int. Geosci. Remote Sens. Symp. (IGARSS) 3, 186-189. http://dx.doi.org/ 10.1109/IGARSS.2008.4779314.

Grossi, M., Valks, P., Loyola, D., Aberle, B., Slijkhuis, S., Wagner, T., Beirle, S., Lang, R., 2015. Total column water vapour measurements from GOME-2 MetOp-A and MetOpB. Atmos. Meas. Tech. 8, 1111-1133. http://dx.doi.org/10.5194/amt-8-1111-2015.

Hagan, D.E., Webster, C.R., Farmer, C.B., May, R.D., Herman, R.L., Weinstock, E.M., Christensen, L.E., Lait, L.R., Newman, P.A., 2004. Validating AIRS upper atmosphere water vapor retrievals using aircraft and balloon in situ measurements. Geophys. Res. Lett. 31, 10-13. http://dx.doi.org/10.1029/2004GL020302.

Hanssen, R.F., Feijt, A.J., Klees, R., 2001. Comparison of precipitable water vapor observations by spaceborne radar interferometry and meteosat $6.7-\mu$ mradiometry. $\mathrm{J}$. Atmos. Oceanic Tech. 18, 756-764. http://dx.doi.org/10.1175/1520-0426(2001) $058<0756$ :COPWVO > 2.0.CO;2.

Ichoku, C., Levy, R., Kaufman, Y.J., Remer, L.A., Li, R.R., Martins, V.J., Holben, B.N., Abuhassan, N., Slutsker, I., Eck, T.F., Pietras, C., 2002. Analysis of the performance characteristics of the five-channel Microtops II Sun photometer for measuring aerosol optical thickness and precipitable water vapor. J. Geophys. Res.-Atmos. 107. http:// 
dx doi.org/10.1029/2001JD001302.

Jones, A., Urban, J., Murtagh, D.P., Eriksson, P., Brohede, S., Haley, C., Degenstein, D. Bourassa, A., Von Savigny, C., Sonkaew, T., Rozanov, A., Bovensmann, H., Burrows, J., 2009. Evolution of stratospheric ozone and water vapour time series studied with satellite measurements. Atmos. Chem. Phys. Discuss 9, 1157-1209. http://dx.doi. org/10.5194/acpd-9-1157-2009.

Kalakoski, N., Kujanpää, J., Sofieva, V., Tamminen, J., Grossi, M., Valks, P., 2016. Validation of GOME-2/Metop total column water vapour with ground-based and in situ measurements. Atmos. Meas. Tech. 9, 1533-1544. http://dx.doi.org/10.5194/ amt-9-1533-2016.

Kalakoski, N., Wagner, T., Mies, K., Beirle, S., Slijkhuis, S., Loyola, D., 2011. O3M Saf Validation Report. Technical Report 2/2011. . http://o3msaf.fmi.fi/docs/vr/ Validation_Report_OTO_H2O_Mar_2011.pdf.

King, M.D., Kaufman, Y.J., Menzel, W.P., Tanré, D., 1992. Remote sensing of cloud, aerosol, and water vapor properties from the Moderate Resolution Imaging Spectrometer (MODIS). IEEE Trans. Geosci. Remote Sens. 30, 2-27. http://dx.doi. org $/ 10.1109 / 36.124212$

Kokhanovsky, A.A., Rozanov, V.V., 2008. The uncertainties of satellite DOAS total ozone retrieval for a cloudy sky. Atmos. Res. 87, 27-36. http://dx.doi.org/10.1016/j. atmosres.2007.04.006.

Leick, A., 1995. GPS Satellite Surveying. Wiley.

Levelt, P.F., van den Oord, G.H.J., Dobber, M.R., Malkki, A., Visser, H., de Vries, J., Stammes, P., Lundell, J.O.V., Saari, H., 2006. The ozone monitoring instrument. IEEE Trans. Geosci. Remote Sens. 44, 1093-1101.

Li, Z., Muller, J.P., Cross, P., 2003. Comparison of precipitable water vapor derived from radiosonde, GPS, and Moderate-Resolution Imaging Spectroradiometer measurements. J. Geophys. Res. Atmos. 108. http://dx.doi.org/10.1029/2003JD003372.

Milstein, A.B., Blackwell, W.J., 2016. Neural network temperature and moisture retrieval algorithm validation for AIRS/AMSU and CrIS/ATMS. J. Geophys. Res. Atmos. 121, 1414-1430. http://dx.doi.org/10.1002/2015JD024008.

Myhre, G., Shindell, D., Bréon, F.-M., Collins, W., Fuglestvedt, J., Huang, J., Koch, D., Lamarque, J.-F., Lee, D., Mendoza, B., Nakajima, T., Robock, A., Stephens, G., Takemura, T., Zhang, H., 2013. Anthropogenic and Natural Radiative Forcing. Technical Report. http://dx.doi.org/10.1017/СBO9781107415324.018.

Niell, A.E., 2000. Improved atmospheric mapping functions for VLBI and GPS. Earth, Planets and Space 52, 699-702. http://dx.doi.org/10.1186/BF03352267.

Ningombam, S.S., Jade, S., Shrungeshwara, T.S., Song, H.J., 2016. Validation of water vapor retrieval from Moderate Resolution Imaging Spectro-radiometer (MODIS) in near infrared channels using GPS data over IAO-Hanle, in the trans-Himalayan region. J. Atmos. Sol. Terr. Phys. 137, 76-85. http://dx.doi.org/10.1016/j.jastp.2015 11.019.

Noël, S., Buchwitz, M., Bovensmann, H., Burrows, J.P., 2005. Validation of SCIAMACHY AMC-DOAS water vapour columns. Atmos. Chem. Phys. 5, 1835-1841. http://dx.doi. org/10.5194/acp-5-1835-2005.

Noël, S., Buchwitz, M., Burrows, J.P., 2004. First retrieval of global water vapour column amounts from SCIAMACHY measurements. Atmos. Chem. Phys. 4, 111-125. http:// dx.doi.org/10.5194/acp-4-111-2004.

Noël, S., Mieruch, S., Bovensmann, H., Burrows, J.P., 2008. Preliminary results of GOME2 water vapour retrievals and first applications in polar regions. Atmos. Chem. Phys. 8, 1519-1529. http://dx.doi.org/10.5194/acp-8-1519-2008.

Olsen, E.T., Blaisdell, J., Iredell, L., Susskind, J., 2013a. AIRS/AMSU/HSB Version 6 Retrieval Flow. Technical Report. Jet Propulsion Laboratory.

Olsen, E.T., Fetzer, E., Hulley, G., Manning, E., Blaisdell, J., Iredell, L., Susskind, J., Warner, J., Wei, Z., Blackwell, W., Maddy, E., 2013b. AIRS / AMSU / HSB Version 6 Level 2 Product User Guide. Technical Report.

Ortiz de Galisteo, J.P., Bennouna, Y., Toledano, C., Cachorro, V., Romero, P., Andrés, M.I., Torres, B., 2014. Analysis of the annual cycle of the precipitable water vapour over Spain from 10-year homogenized series of GPS data. Q. J. R. Meteorol. Soc. 140, 397-406. http://dx.doi.org/10.1002/qj.2146.

Ortiz de Galisteo, J.P., Cachorro, V., Toledano, C., Torres, B., Laulainen, N., Bennouna, Y., de Frutos, A., 2011. Diurnal cycle of precipitable water vapor over Spain. Q. J. R. Meteorol. Soc. 137, 948-958. http://dx.doi.org/10.1002/qj.811.

Ortiz de Galisteo, J.P., Toledano, C., Cachorro, V., Torres, B., 2010. Improvement in PWV estimation from GPS due to the absolute calibration of antenna phase center variations. GPS Solutions 14, 389-395. http://dx.doi.org/10.1007/s10291-010-0163-y.

Pany, T., Pesec, P., Stangl, G., 2001. Atmospheric GPS slant path delays and rays tracing through numerical weather models, a comparison. Phys. Chem. Earth Solid Earth Geod. 26, 183-188. http://dx.doi.org/10.1016/S1464-1895(01)00044-8.

Pérez-Ramírez, D., Navas-Guzmán, F., Lyamani, H., Fernández-Gálvez, J., Olmo, F.J., Alados-Arboledas, L., 2012. Retrievals of precipitable water vapor using star photometry: assessment with Raman lidar and link to sun photometry. J. Geophys. Res. Atmos. 117, 1-10. http://dx.doi.org/10.1029/2011JD016450.

Prasad, A.K., Singh, R.P., 2009. Validation of MODIS Terra, AIRS, NCEP/DOE AMIP-II Reanalysis-2, and AERONET Sun photometer derived integrated precipitable wate vapor using ground-based GPS receivers over India. J. Geophys. Res. Atmos. 114, 1-20. http://dx.doi.org/10.1029/2008JD011230.

Rama Varma Raja, M.K., Gutman, S.I., Yoe, J.G., McMillin, L.M., Zhao, J., 2008. The validation of AIRS retrievals of integrated precipitable water vapor using measurements from a network of ground-based GPS receivers over contiguous United States. J. Atmos. Ocean. Technol. 25, 416-428. http://dx.doi.org/10.1175/ 2007JTECHA889.1.
Rohm, W., Yuan, Y., Biadeglgne, B., Zhang, K., Marshall, J.L., 2014. Ground-based GNSS ZTD/IWV estimation system for numerical weather prediction in challenging weather conditions. Atmos. Res. 138, 414-426. http://linkinghub.elsevier.com/retrieve/pii/ S0169809513003499http://dx.doi.org/10.1016/j.atmosres.2013.11.026.

Román, R., Antón, M., Cachorro, V.E., Loyola, D., Ortiz de Galisteo, J.P., de Frutos, A., Romero-Campos, P.M., 2015. Comparison of total water vapor column from GOME-2 on MetOp-A against ground-based GPS measurements at the Iberian Peninsula. Sci. Total Environ. 533, 317-328. http://dx.doi.org/10.1016/j.scitotenv.2015.06.124.

Scheepmaker, R.A., Frankenberg, C., Deutscher, N.M., Schneider, M., Barthlott, S., Blumenstock, T., Garcia, O.E., Hase, F., Jones, N., Mahieu, E., Notholt, J., Velazco, V., Landgraf, J., Aben, I., 2015. Validation of sciamachy HDO/H2O measurements using the TCCON and NDACC-MUSICA networks. Atmos. Meas. Tech. 8, 1799-1818. http://dx.doi.org/10.5194/amt-8-1799-2015.

Schrijver, H., Gloudemans, A.M.S., Aben, I., 2009. Water vapour total columns from SCIAMACHY spectra in the $2.36 \mathrm{mu}$ m window. Atmos. Meas. Tech. 2, 561-571. http://dx.doi.org/10.5194/amt-2-561-2009.

Schroedter-Homscheidt, M., Drews, A., Heise, S., 2008. Total water vapor column retrieval from MSG-SEVIRI split window measurements exploiting the daily cycle of land surface temperatures. Remote Sens. Environ. 112, 249-258. http://dx.doi.org/ 10.1016/j.rse.2007.05.006.

Seemann, S.W., Li, J., Menzel, W.P., Gumley, L.E., 2003. Operational retrieval of atmospheric temperature, moisture, and ozone from MODIS infrared radiances. J. Appl. Meteor. 42, 1072-1091.

Torres, B., Cachorro, V.E., Toledano, C., Ortiz De Galisteo, J.P., Berjón, A., De Frutos, A.M., Bennouna, Y., Laulainen, N., 2010. Precipitable water vapor characterization in the Gulf of cadiz region (southwestern Spain) based on Sun photometer, GPS, and radiosonde data. J. Geophys. Res. Atmos. 115, 1-11. http://dx.doi.org/10.1029/ 2009JD012724.

Turner, D.D., Clough, S.A., Liljegren, J.C., Clothiaux, E.E., Cady-Pereira, K.E., Gaustad, K.L., 2007. Retrieving liquid water path and precipitable water vapor from the atmospheric radiation measurement (ARM) microwave radiometers. In: IEEE Transactions on Geoscience and Remote Sensing. vol. 45. pp. 3680-3689. http://dx. doi.org/10.1109/TGRS.2007.903703.

Turner, D.D., Ferrare, R.A., Heilman Brasseur, L.A., Feltz, W.F., Tooman, T.P., 2002. Automated retrievals of water vapor and aerosol profiles from an operational Raman lidar. J. Atmos. Ocean. Technol. 19, 37-50. http://dx.doi.org/10.1175/15200426(2002)019<0037:AROWVA> 2.0.CO;2.

Vaquero-Martínez, J., Antón, M., Ortiz de Galisteo, J.P., Cachorro, V.E., Costa, M.J., Román, R., Bennouna, Y.S., 2017a. Validation of MODIS integrated water vapor product against reference GPS data at the Iberian Peninsula. Int. J. Appl. Earth Obs. Geoinf. 63, 214-221. http://linkinghub.elsevier.com/retrieve/pii/ S0048969716327176http://dx.doi.org/10.1016/j.jag.2017.07.008.

Vaquero-Martínez, J., Antón, M., Ortiz de Galisteo, J.P., Cachorro, V.E., Wang, H. González Abad, G., Román, R., Costa, M.J., 2017b. Validation of integrated water vapor from OMI satellite instrument against reference GPS data at the Iberian Peninsula. Sci. Total Environ. 580, 857-864. http://linkinghub.elsevier.com/ retrieve/pii/S0048969716327176http://dx.doi.org/10.1016/j.scitotenv.2016.12 032

Wagner, T., Beirle, S., Deutschmann, T., 2009. Three-dimensional simulation of the Ring effect in observations of scattered sun light using Monte Carlo radiative transfer models. Atmos. Meas. Tech. 2, 113-124. http://www.atmos-_meas-_tech.net/2/113/ 2009/http://dx.doi.org/10.5194/amt-2-113-2009.

Wagner, T., Beirle, S., Grzegorski, M., Platt, U., 2006. Global trends (1996-2003) of total column precipitable water observed by Global Ozone Monitoring Experiment (GOME) on ERS-2 and their relation to near-surface temperature. J. Geophys. Res. Atmos. 111, 1-15. http://dx.doi.org/10.1029/2005JD006523.

Wagner, T., Heland, J., Zöger, M., Platt, U., 2003. A fast $\mathrm{H}<$ sub $>2</$ sub $>\mathrm{O}$ total column density product from GOME \& ndash; validation with in-situ aircraft measurements. Atmos. Chem. Phys. Discuss. 3, 323-353. http://dx.doi.org/10.5194/ acpd-3-323-2003.

Wang, H., Gonzalez Abad, G., Liu, X., Chance, K., 2016a. Validation of OMI total column water vapor product. Atmos. Chem. Phys. Discuss. 181, 1-23. http://dx.doi.org/10. 5194/acp-2016-181.

Wang, H., Liu, X., Chance, K., González Abad, G., Chan Miller, C., 2014. Water vapor retrieval from OMI visible spectra. Atmos. Meas. Tech. 7, 1901-1913. http://dx.doi. org/10.5194/amt-7-1901-2014.

Wang, X., Zhang, K., Wu, S., Fan, S., Cheng, Y., 2016b. Water vapor-weighted mean temperature and its impact on the determination of precipitable water vapor and its linear trend. J. Geophys. Res. Atmos. 121, 833-852. http://doi.wiley.com/10.1002/ 2015JD024181http://dx.doi.org/10.1002/2015JD024181.

Wang, X., Zhang, K., Wu, S., He, C., Cheng, Y., Li, X., 2016c. Determination of zenith hydrostatic delays and the development of new global long-term GNSS-derived precipitable water vapor. Atmos. Meas. Tech. Discuss. 10, 1-17. http://www.atmosmeas- tech- discuss.net/amt- 2016- 264/http://dx.doi.org/10.5194/amt-2016-264.

Wilcoxon, F., 1946. Individual comparisons of grouped data by ranking methods. J. Econ. Entomol. 39, 269. http://dx.doi.org/10.2307/3001968.

du Piesanie, A., Piters, A.J.M., Aben, I., Schrijver, H., Wang, P., Noël, S., 2013. Validation of two independent retrievals of sciamachy water vapour columns using radiosonde data. Atmos. Meas. Tech. 6, 2925-2940. http://www.atmos-_meas-_tech.net/6/ 2925/2013/http://dx.doi.org/10.5194/amt-6-2925-2013. 